\title{
THE FOLLOW-UP OF DIABETIC PATIENTS UNDER A PRIMARY CARE PROGRAM IN THE CITY OF RIO BRANCO - ACRE - BRAZIL
}

1 Daniela Neves Fernandes do Vale

1,2 Luís Eduardo Maggi

1,3 Wagner Coelho de Albuquerque Pereira danganeves@hotmail.com

luis.maggi@ufac.br

wagner@peb.ufrj.br

1 Programa de Pós-Graduação em Ciências da Saúde na Amazônia Ocidental, Centro de Ciências da Saúde e do Desporto. Universidade Federal do Acre. Rio Branco, AC, Brazil

2 Centro de Ciências Biológicas e da Natureza, Universidade Federal do Acre, Rio Branco, Acre, Brazil

Programa de Engenharia Biomédica - COPPE, Universidade Federal do Rio de Janeiro. Rio de Janeiro, RJ, Brazil

\begin{abstract}
Aims: Analyze the monitoring of patients with Diabetes Mellitus treated in the Family Health Strategy in the city Rio Branco, Acre State, Brazil. Methods: The study is observational, analytical, cross-sectional research with a quantitative approach. Held from January 2015 to December 2016, in 12 health units (Family Health Strategy ESF), in the city of Rio Branco, Acre. For data collection, a simple random drawing of a Family Health Group from each Health segment was carried out. After the drawing, a Verification Form was applied, developed from the recommendations of the Ministry of Health for monitoring diabetic patients. Results: In the 306 records analyzed, there was a predominance of females (68\%), with an average age of 61.6 \pm 13 years. As for the metabolic control variables, the most prevalent test was fasting blood glucose (85\%), with an average of $211.6 \mathrm{mg} / \mathrm{dl}$. Regarding the number of medical consultations per year, in 2015, 216 consultations were carried out, with $36.9 \%$ of patients having three or more consultations/year, this number rose to 253 in 2016, with more than 3 consultations/year (48.1\%). Metformin was the most used medication (77.8\%), followed by Glibenclamide (53.3\%) and insulin (22\%). Conclusions: FHS groups in the city of Rio Branco, Acre partially follow the guidelines of the Ministry of Health in monitoring diabetic patients. The motives for that are yet to be evaluated, nevertheless, it can have an unfavorable impact on their quality of life.
\end{abstract}

Keywords: Diabetes Mellitus. Primary Health Care. Family Health Strategy. 


\section{INTRODUCTION}

Diabetes Mellitus (DM) is a disease of multifactorial origin that affects the metabolism of the living being and is characterized by excess sugar in the bloodstream, produced by a metabolic disorder in carbohydrates, proteins, and fats, which is caused by the failure of secretion and/or insulin action(1).

The most frequent clinical forms are type-2 diabetes mellitus (DM2), which represents 85 to $90 \%$ of the cases, followed by type- 1 diabetes mellitus (DM1), which corresponds to 5 to $10 \%$, other the less frequent forms are responsible for very small numbers of this disease(2). DM1 is characterized by the absolute lack of the hormone produced by the pancreas (insulin) and is primarily manifested in children and adolescents. DM2 is related to the relative absence of insulin associated with a deficiency in its secretion, this form of diabetes is related to poor eating habits and physical inactivity(3).

A sudden increase in the number of DM cases has been occurring in the world population. It is estimated that it is of the order of 415 million and that it will reach more than 642 million individuals by the year 2040. In Brazil, the number of patients with this disease was 14.3 million in 2015, ranking first among Central and South American countries, and, when related to the number of children affected by diabetes, occupies the third position, just below the United States and India(4).

Due to the significant increase in diabetes cases in the last decades, this disease has been considered as a Sensitive Condition to Primary Care (SCPC)(5). Scientific studies reveal that adequate management of this problem even in Primary Care (PC) prevents hospitalizations and deaths due to vascular complications of the brain and heart(6).

The Family Health Strategy Program (FHS), implemented in Brazil by the Ministry of Health, initially called Family Health Program (FHP), in 1994, aims to improve the organization of $\mathrm{PC}$ in Brazil, in line with the doctrines of the Unified Health System (SUS - Sistema Único de Saúde)(7).

This model is considered by the Ministry of Health, state and municipal managers as a strategy for the expansion, qualification, and strengthening of PC as it reinforces a reorientation in the work process with a greater capacity to intensify the bases, guidelines, and foundations of PC, as well as increasing the resolution and impact on the health of individuals and/or social groups, in addition to providing 
excellent cost-effectiveness(7).

The use of instructions and guidelines, in addition to the care routines supported by scientific evidence by health groups, is directly related to the best quality of care, with the aim of obtaining better health results. A major current problem for the Family Health Strategy (FHS) teams in the health care for chronic diseases(8).

In this context, the Ministry of Health has been improving guidelines, methodologies, and instruments to support the FHS groups, such as, for example, the Primary Care Booklets (PCB), aiming at comprehensive care, health promotion, prevention of development of chronic diseases and their complications and treatment. Regarding our study, there is the PCB $n^{\circ} 36$, entitled "Strategies for the care of people with chronic illness: Diabetes Mellitus"(8).

Given the above scenario, this study aims to analyze the follow-up of patients with Diabetes Mellitus treated at the Family Health Strategy Program in the city of Rio Branco, Acre, Brazil, in the years 2015 - 2016.

\section{MATERIAL AND METHODS}

The following study is observational, analytical, and cross-sectional research, with a quantitative approach. The study was carried out in the city of Rio Branco, capital of the state of Acre, located in the North of the country, in the Western Brazilian Amazon. Its population, according to the Brazilian Institute of Geography and Statistics (IBGE - Instituto Brasileiro de Geografia e Estatística), is 383,443 inhabitants (08/30/2017). The health services in this city are basically public (SUS), the private sector is still scarce.

In Rio Branco, Primary Care (PC) is divided into 13 Health Segments and has 62 Family Health Groups, located in the city's administrative regions.

The population of diabetics in Rio Branco was about 7,500 patients registered in the E-SUS system, according to data from the technical area of Hypertension and Diabetes in the municipality (December/2016). The sample size was 366 individuals obtained by the online calculator(9).

To reach this number, the sample was selected by a simple random drawing of one Family Health Group by Health segment and, subsequently, another random drawing performed to obtain at least 30 records per group. Inclusion criteria were: 
Being 18 years of age or older and carrier of Diabetes mellitus; Be from the assigned area of the Family Health Group and be accompanied by the FHS program. The exclusion team: patients with gestational diabetes.

After the drawing of the Family Health Groups and medical records, a Verification Form (VF) developed by the researchers was applied, based on the recommendations of the Ministry of Health, as expressed on the Primary Care Booklet $\mathrm{n}^{\circ} 36$.

This VF consists of sociodemographic variables (gender, age, occupation, education, marital status), clinical variables (weight, height, known time of diagnosis, number of medical and nursing consultations/year, risk factors, complications, Mass Index Corporeal, abdominal circumference), metabolic control variables (Blood Pressure values and complementary tests such as total cholesterol and fractions, fasting glycemia, glycated hemoglobin, triglycerides, creatinine, microalbuminuria) and treatment variables (non-pharmacological, pharmacological).

For data analysis, a database was prepared in a spreadsheet, containing the sociodemographic, clinical, metabolic control, and treatment variables, based on patient records. A descriptive analyzes were made from all the variables contained in the form and the percentages of each existing information were calculated.

The present work had the prior approval of the Ethics and Research Committee of the Federal University of Acre (CEP / UFAC) under the number: $1,884,242$.

\section{RESULTS}

A total of 306 medical records from 12 units of the Family Health Strategy were analyzed. Regarding the 13 health segments in Rio Branco, it was not possible to collect data from segment 6 since it started using electronic medical records and we were not able to access the physical records of the years 2015 and 2016 . Additionally, segments 1 and 3 had only 16 patients registered with DM, and segment 5 , only 22 patients.

Regarding sociodemographic variables, concerning gender, there was a predominance of females (68\%), as for the age of patients, the lowest was 19 years and the highest was 97 years old, with an average age of $61.6 \pm 13.0$ years. The 
assessment of educational level, marital status, and occupation was compromised due to the absence of this data in the patients' medical records. Among the data that had this information, the schooling that most prevailed was Incomplete Elementary School (6.4\%) and marital status was married (26.1\%), (Table 1).

Table 1 - Sociodemographic characteristics of patients with DM treated at the FHS from January 2015 to December 2016 in Rio Branco, Acre, Brazil

\begin{tabular}{|c|c|c|c|}
\hline \multicolumn{2}{|c|}{ VARIABLES } & $\mathbf{n}$ & $\%$ \\
\hline \multirow{2}{*}{ Gender } & Female & 208 & 68.0 \\
\hline & Male & 98 & 32.0 \\
\hline \multirow{3}{*}{ Age (years) } & $20-39$ & 17 & 5.6 \\
\hline & $40-59$ & 102 & 33.3 \\
\hline & $\geq 60$ & 187 & 61.1 \\
\hline \multirow{5}{*}{ Civil Status } & Married & 80 & 26.1 \\
\hline & Single & 18 & 5.9 \\
\hline & Widow/Widower & 14 & 4.6 \\
\hline & Divorced & 4 & 1.3 \\
\hline & No Information & 190 & 62.1 \\
\hline \multirow{7}{*}{ Literacy } & Illiterate & 8 & 2.6 \\
\hline & IES & 20 & 6.4 \\
\hline & CES & 2 & 0.7 \\
\hline & IHS & 1 & 0.3 \\
\hline & $\mathrm{CHS}$ & 2 & 0.7 \\
\hline & CHEd & 1 & 0.3 \\
\hline & $\begin{array}{c}\text { No } \\
\text { Information }\end{array}$ & 272 & 89.0 \\
\hline
\end{tabular}

IES = Incomplete Elementary School; CES = Complete Elementary School; IHS = Incomplete High School; CHS = Complete High School; CHEd = Complete Higher Education.

The clinical, anthropometric, and metabolic control parameters of the patients are shown in Table 2. The most prevalent type of Diabetes was type II DM (99\%). The anthropometric data and the clinical variables were not noted in most medical records, which is why it was not possible to analyze these data. Only the weight $(51 \%)$ was present in the studied sample, and the average was $76.2 \pm 17.8 \mathrm{~kg}$. As for the metabolic control variables, the most prevalent test was the blood glucose fasting (85\%), and the average was $211.6 \mathrm{mg} / \mathrm{dl}$, the other tests had few records, limiting the analysis. 
Table 2 - Clinical and metabolic control variables of patients with DM treated at the FHS from January 2015 to December 2016 in Rio Branco, Acre, Brazil

\section{MEDICAL RECORD INFORMATION}

\begin{tabular}{clcc}
\hline CATEGORY & VARIABLES & $\begin{array}{c}\text { PRESENT } \\
\mathbf{n}(\%)\end{array}$ & $\begin{array}{c}\text { ABSENT } \\
\mathbf{n}(\%)\end{array}$ \\
\hline & Weight & $156(51.0)$ & $150(49.0)$ \\
Clinical Variables & Height & $93(30.4)$ & $213(69.6)$ \\
& BMI & $13(4.2)$ & $293(95.8)$ \\
& AC & $18(5.9)$ & $288(94.1)$ \\
& Foot Evaluation & $16(5.2)$ & $290(94.8)$ \\
\hline \multirow{3}{*}{ Complementary } & Glucose & $261(85.3)$ & $45(14.7)$ \\
& Total cholesterol & $80(26.1)$ & $226(73.9)$ \\
& Triglycerides & $77(25.2)$ & $229(74.8)$ \\
& HbA1C & $54(17.6)$ & $252(82.4)$ \\
& Creatinine & $46(15.0)$ & $260(85.0)$ \\
& Cholesterol Hdl & $35(11.4)$ & $271(88.1)$ \\
& Cholesterol Ldl & $34(11.1)$ & $272(88.9)$
\end{tabular}

$\mathrm{BMI}=$ Body Mass Index; $\mathrm{AC}=$ abdominal circumference; HbA1C = Glycated Hemoglobin; $\mathrm{Hdl}=$ High Density Lipoproteins; $L d \mathrm{dl}=$ Low Density Lipoproteins.

As for the number of medical appoitments per year, in 2015, 306 consultations were carried out, with $36.9 \%$ of patients having 3 to more consultations/year, this number rose to $48.1 \%$ with more than 3 consultations/year in 2016 . There was still a considerable number of patients for whom no consultation was registered/year (Table 3). 
Table 3 - Number of medical appointments per year of patients with DM treated at the FHS from January 2015 to December 2016 in Rio Branco, Acre, Brazil

\begin{tabular}{|c|c|c|}
\hline \multirow{3}{*}{$\begin{array}{l}\text { № of medical } \\
\text { appointments }\end{array}$} & \multicolumn{2}{|c|}{ YEAR } \\
\hline & 2015 & 2016 \\
\hline & $n(\%)$ & $n(\%)$ \\
\hline Unfilled & $90(29.4)$ & $53(17.3)$ \\
\hline 1- 2 & 103(33.7) & $106(34.6)$ \\
\hline $3-4$ & $66(21.6)$ & $80(26.1)$ \\
\hline $5-6$ & $26(8.5)$ & $39(12.8)$ \\
\hline $7-8$ & $19(6.2)$ & $18(5.9)$ \\
\hline$>8$ & $2(0.6)$ & $10(3.3)$ \\
\hline Total & $306(100)$ & $306(100)$ \\
\hline
\end{tabular}

The main risk factors found related to DM2 were arterial hypertension (42\%), followed by overweight and obesity (27\%), and dyslipidemia (20\%). Unfortunately, the analysis of these data was impaired, and it was not possible to present the actual percentages, due to the high number of information missing from the medical records (Table 4).

As for chronic complications, only $3.6 \%$ of medical records contained information about the presence of nephropathy, the information about diabetic foot was present in $3.9 \%$ and about stroke (3.6\%). Once again, it is highlighted that there was a great lack of information on these variables (Table 4). 
Table 4 - Risk factors and complications of patients with DM treated at the FHS from January 2015 to December 2016 in Rio Branco, Acre, Brazil

MEDICAL RECORD INFORMATION

\begin{tabular}{cccc}
\hline \multirow{2}{*}{ CATEGORY } & VARIABLES & $\begin{array}{c}\text { PRESENT } \\
\mathbf{n}(\%)\end{array}$ & $\begin{array}{c}\text { ABSENT } \\
\mathbf{n}(\%)\end{array}$ \\
\hline & Hypertension & $130(42.4)$ & $176(57.6)$ \\
& Dyslipidemia & $62(20.3)$ & $244(79.7)$ \\
\cline { 2 - 4 } Risck Factors & Overweight & $46(15.0)$ & $260(85.0)$ \\
\cline { 2 - 4 } & Obesity & $37(12.1)$ & $269(87.9)$ \\
\cline { 2 - 4 } & Sedentary lifestyle & $28(9.2)$ & $278(90.8)$ \\
\cline { 2 - 4 } & Smoking & $17(5.6)$ & $289(94.4)$ \\
\cline { 2 - 4 } Microvascular & Alcoholism & $0(0)$ & $100(100)$ \\
\cline { 2 - 4 } Complications & Nephropathy & $11(3.6)$ & $295(96.4)$ \\
\cline { 2 - 4 } & Neuropathy & $3(1.0)$ & $303(99.0)$ \\
\hline \multirow{2}{*}{ Macrovascular } & Retinopathy & $1(0.3)$ & $305(99.7)$ \\
\cline { 2 - 4 } Complications & Diabetic foot & $12(3.9)$ & $294(96.1)$ \\
\cline { 2 - 4 } & VS & $11(3.6)$ & $295(96.4)$ \\
\cline { 2 - 4 } & AMl & $8(2.6)$ & $298(97.4)$
\end{tabular}

$\mathrm{V}=$ Vascular Stroke; $\mathrm{AMI}=$ Acute Myocardial Infarction

Finally, in the analysis of treatment variables, most patients used only oral antidiabetic drugs (74.9\%), of these $47.7 \%$ used Metformin combined with Glibenclamide, 18 (5.9\%) associated Metformin with Insulin and 5.2\% Metformin with Glibenclamide and Insulin. Glibenclamide was also used by $8.2 \%$ of patients as monotherapy and $21.9 \%$ used Insulin. 32 (10.5\%) using only insulin (Table 5). 
Table 2: Treatment variables of patients with DM treated at the FHS from January 2015 to December 2016 in Rio Branco, Acre, Brazil

TREATMENT VARIABLES

\begin{tabular}{lcc}
\hline MEDICINES & $\mathbf{n}$ & \% \\
\hline Metformin + Glibenclamide & 146 & 47.7 \\
\hline Metformin & 58 & 19.0 \\
\hline Insulin & 32 & 10.5 \\
\hline Glibenclamide & 25 & 8.2 \\
\hline Metformin + Insulin & 18 & 5.9 \\
\hline Metformin + Glibenclamide + Insulin & 16 & 5.2 \\
\hline Glibenclamide + Insulin & 1 & 0.3 \\
\hline No Information & 10 & 3.2 \\
\hline
\end{tabular}

\section{DISCUSSIONS}

Regarding sociodemographic variables, the study showed predominance of females. It is noteworthy that, in several studies conducted with people with diabetes, a higher frequency of females was also found (10-17).

About the age of the participants in this research, the average age above 60 years was similar to that found in others $(11,13-16,18-20)$. This fact may be due to the increase in the prevalence of diabetes with advancing of the age $(21,22)$.

The analysis of occupation and education level of the studied population were hampered by the lack of this kind of data in the medical records. However, those who information was filled shows prevalence to low level of education in agreement with other studies, where the prevalence of such education level in patients with diabetes was predominant $(10,11,15,16,20,23,24)$. These patients' low educational level can hinder their access to information and may be related to the difficulty of managing health care and adherence to the therapeutic plan(15).

Regarding clinical variables, the most prevalent type of DM was DM2. These data are in agreement with the Brazilian Diabetes Society, which points out that DM1 is present in 5 to $10 \%$ of the population and DM2 in 90 to $95(2,25)$. One of the most important clinical variables, which had its analysis compromised due to the lack of data in the medical records was body weight. In this study, from the $51 \%$ of the medical records that contained this information, more than half were overweight or 
obese. It is known that excess body weight is the most important risk factor for developing type 2 diabetes and that most patients with type of the disease are overweight or obese. Studies carried out with diabetic patients have observed overweight or obesity in the participants $(10,13)$.

The most frequent risk factor found in the present study was arterial hypertension (SAH). Its prevalence in this study draws attention because it is extremely high, despite not having the information of all participants, a fact that was also found in several other studies $(11,26)$.

Concerning the metabolic control variables, it was not possible to know whether the patients had adequate control or not, since the complementary tests were not noted in the medical records.

Among the tests recommended in the monitoring of diabetic patients, the most prevalent one was glycemia, even so, $15 \%$ of these patients did not even have blood glucose recorded. The other tests had few records, limiting the analysis of metabolic control. As the average blood glucose is above the values recommended by American Diabetes Association, it can be assumed these patients do not have good metabolic control and they are not being properly cared for. It is important to remember that it is unacceptable for a patient not to have their blood glucose recorded in a 2-year interval.

Regarding the number of medical consultations carried out, it was observed that the individual with chronic diseases is usually a major user of the Basic Health Unit. In this study, 36.9\% of patients had 3 or more consultations/year in 2015 and 48.1\% in 2016. The normative instrument of the Ministry of Health (MS) recommends that the monitoring of these patients be done in three or four consultations per year, according to the risks that each individual presents (5). Regarding the nursing consultations, no analysis could be made, since only 21 nursing consultations were observed during the study period. This event differs from the recommendations of the Ministry of Health since the nursing consultation to assist these patients is part of the protocol. In addition, this consultation focuses on the health education process to help the individual to live better with their chronic condition and develop autonomy for their care (5).

Regarding the treatment variables, all participants underwent pharmacological treatment. The oral antidiabetics (ADO) used in the most frequent treatment were 
from the Biguanide group, with Metformin being its representative, followed by the sulfonylureas that had Glibenclamide. Among the injectable medications, the most prevalent was slow-acting insulin (PHN). These medications were used as monotherapy or in combination with each other. In line with this study, several studies also found similar results $(10,15,20)$ The use of these drugs must be related to the public policy of free distribution of medicines by the SUS.

Knowing how the assistance of diabetics is being carried out is of fundamental importance to know at which points it is necessary to make modifications, to guarantee an effective intervention and to improve the quality of life of these patients.

The study carried out presented important limitations that hindered data collection and its subsequent analyzes, since the medical records did not contain important information at various levels, such as identification, clinical data, complementary exams, and guidance provided to patients. The lack of data in the medical records makes it impossible for the group in charge to make an adequate follow-up, especially due to the high turnover of health professionals, mainly doctors, and nurses.

\section{CONCLUSION}

The results allowed us to conclude that the Family Health Strategy groups do not adequately follow the guidelines of the Ministry of Health, according to the Primary Care Booklet $n^{\circ} 36$ when monitoring diabetic patients. The reasons for such behavior were not the object of this study, but there is certainly an impact on the epidemiological monitoring of DM, limiting a more complete assessment of these populations, as well as planning and correcting the direction of health policies.

Many missing data in the medical records made it impossible to analyze several aspects of the studied population. Regarding metabolic control, it was not possible to evaluate these patients, it was also impossible to know the risk factors and complications they already have, which makes it difficult to have an expanded view of the monitoring of these patients, as well as promoting care and strategic planning to achieve glycemic goals and, consequently, control of the disease and its complications.

In view of these results, some suggestions can be offered to facilitate 
compliance with health indicators and objectives. The first of these would be the development of software aimed at the registration of diabetic patients and their monitoring, which has redundancies and alerts so that it is finalized only when all the information is essential to their registration and monitoring. This software could generate alerts to health professionals about missing patients so that there is an active search by the group.

Regular control of the Diabetes Technical area in Health Units is also suggested, to detect and minimize problems. It is also recommended that future studies related to the care and monitoring of patients with diabetes in Primary Care be carried out, especially if the software suggestion is implemented, to evaluate both its effectiveness and the situation of the patients' metabolic control.

\section{REFERENCES}

1. WHO. Definition, diagnosis, and classification of Diabetes Mellitus and its Complications. Ameliorating Mental Disability: Questioning Retardation. Geneva, Switzerland; 2017. p. 1-19.

2. American Diabetes Association. Diagnosis and classification of diabetes mellitus. Diabetes Care. 2014;37(SUPPL.1):81-90.

3. Oliveira JEP de, Júnior RMM, Vencio S. Diretrizes Sociedade Brasileira de Diabetes 2017-2018 [Internet]. Editora C, Científica, editors. Sao Paulo, SP; 2018. 3-383 p. Available from: https://www.diabetes.org.br/profissionais/images/2017/diretrizes/diretrizes-sbd2017-2018.pdf

4. International Diabetes Federation. Diabetes. Sétima edi. International Diabetes Federation. International Diabetes Federation; 2015. 144 p.

5. Brasil. Ministério da Saúde. Secretaria de Atenção à Saúde. Departamento de Atenção Básica. Estratégias para o cuidado da pessoa com doença crônica: diabetes mellitus. 1a ${ }^{a}$. Brasília: Ministério da Saúde; 2013. 162 p.

6. Alfradique ME, Bonolo PDF, Dourado I, Lima-Costa MF, Macinko J, Mendonça CS, et al. Ambulatory care sensitive hospitalizations: elaboration of Brazilian list as a tool for measuring health system performance (Project ICSAP--Brazil). Cad saude publica / Minist da Saude, Fund Oswaldo Cruz, Esc Nac Saude 
Publica. 2009;25(6):1337-49.

7. Brasil. Ministério da Saúde. Secretaria de Atenção à Saúde. Departamento de Atenção Básica. Política Nacional de Atenção Básica. Vol. I, Ministério da Saúde. 2012. 110 p.

8. Brasil. Ministério da Saúde. Secretaria de Atenção à Saúde. Departamento de Atenção Básica. Estratégias para o cuidado da pessoa com doença crônica. 2014. 162 p.

9. Prática Clínica. Cálculo Amostral [Internet]. 2017 [cited 2021 Jul 15]. Available from: $\quad$ https://www.praticaclinica.com.br/anexos/ccolaborativa-calculoamostral/ccolaborativa-calculo-amostral.php

10. MOREIRA RC. Efeito Do Uso Do Método De Gerenciamento De Caso Sobre O Controle Glicêmico De Pessoas Com Diabetes Mellitus Tipo 2. Vol. 1, Tese. Universidade Federal do Paraná; 2013.

11. Turcatto H, Faria G, Antônio M, Arre- CCA, Zanetti ML. Adherence to Diabetes Mellitus treatments in Family Health Strategy Units. 2014;48(2):257-63.

12. Mielczarski RG, Costa JSD Da, Olinto MTA. Epidemiologia e organização de serviços de saúde: diabetes mellitus numa comunidade de Porto Alegre. Cien Saude Colet. 2012;17(1):71-8.

13. Sousa JT de, Macêdo SF de, Moura JRA, Silva ARV da, Vieira EES, Reis A da $S$ dos. Self-care and clinical parameters in patients with type 2 diabetes mellitus. Rev da Rede Enferm do Nord. 2015;16(4):479-85.

14. Zulian LR, Santos MA, Veras VS, Rodrigues FFL, Arrelias CCA XM. Qualidade de vida de pacientes com diabetes utilizando o instrumento diabetes 39 (d-39). 2013;39(3):138-46.

15. S, Faria HTG, Teixeira CR de S, Santos MA dos, Zanetti, Maria LuciaArrelias CCA. Adesão ao tratamento do diabetes mellitus e variáveis sociodemográficas, clinicas e de controle metabólico. Acta Paul Enferm. 2015;28(4):315-22.

16. Smanioto FN, Fernandez C, Haddad L. Autocuidado nos fatores de risco da ulceração em pés diabéticos : estudo transversal. 2014;13(3):343-52.

17. Pereira DA, Costa NM da SC, Sousa ALL, Zanini CR de O. Efeito de intervenção educativa sobre o conhecimento da doença em pacientes com diabetes melitus. Artigo. 2012;20(3):1-8. 
18. Santos Ade L, Cecilio HP, Teston EF, Arruda GO, Peternella FM, Marcon SS. Microvascular complications in type 2 diabetes and associated factors: a telephone survey of self-reported morbidity. Cien Saude Colet. 2015;20(3):761-70.

19. Santos ICRV, Sobreira CMM, Nunes EN dos Sa, Morais MC de A. Prevalência e fatores associados a amputações por pé diabético. Cien Saude Colet. 2013;18(10):3007-14.

20. Figueira ALG, Boas LCGV, Coelho ACM, Freitas MCF de, Pace AE. Educational interventions for knowledge on the disease, treatment adherence, and control of diabetes mellitus. Rev Lat Am Enfermagem. 2017;25(0).

21. Brasil. Ministério da Saúde. Secretaria de Vigilância em Saúde. Departamento de Vigilância de Doenças e Agravos não, Saúde. T e P da. Vigitel Brasil 2016. 2017. $160 \mathrm{p}$.

22. Iser BPM, Stopa SR, Chueiri PS, Szwarcwald CL, Malta DC, Monteiro HO da $\mathrm{C}$, et al. Prevalência de diabetes autorreferido no Brasil: resultados da Pesquisa Nacional de Saúde 2013. Epidemiol e Serviços Saúde. 2015;24(2):305-14.

23. Malta DC, Santos MAS, Stopa SR, Vieira JEB, Melo EA, Reis AAC dos. A Cobertura da Estratégia de Saúde da Família (ESF) no Brasil, segundo a Pesquisa Nacional de Saúde, 2013. Cien Saude Colet. 2016;21(2):327-38.

24. Alves MG de M, Casotti E, Oliveira LGD de, Machado MTC, Almeida PF de, Corvino MPF, et al. Fatores condicionantes do acesso às equipes da Estratégia Saúde da Família no Brasil. Saúde em Debate. 2014;38(special):34-51.

25. Adolfo Milech et al. Diretrizes da Sociedade Brasileira de Diabetes 2015-2016. Ac Farmacêutica Ltda. 2016. 348 p.

26. Boas LC, Foss-Freitas MC, Pace AE. [Adherence of people with type 2 diabetes mellitus to drug treatment]. Rev Bras Enferm. 2014;67(2):268-73. 